\title{
Simultaneous saccharification and fermentation of steam-exploded corn stover at high glucan loading and high temperature
}

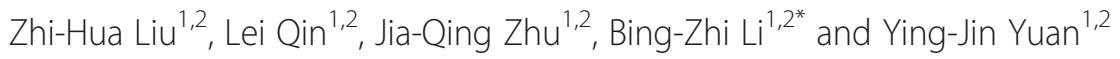

\begin{abstract}
Background: Simultaneous saccharification and fermentation (SSF) is a promising process for bioconversion of lignocellulosic biomass. High glucan loading for hydrolysis and fermentation is an efficient approach to reduce the capital costs for bio-based products production. The SSF of steam-exploded corn stover (SECS) for ethanol production at high glucan loading and high temperature was investigated in this study.

Results: Glucan conversion of corn stover biomass pretreated by steam explosion was maintained at approximately 71 to $79 \%$ at an enzyme loading of 30 filter paper units (FPU)/g glucan, and 74 to $82 \%$ at an enzyme loading of $60 \mathrm{FPU} / \mathrm{g}$ glucan, with glucan loading varying from 3 to 12\%. Glucan conversion decreased obviously with glucan loading beyond $15 \%$. The results indicated that the mixture was most efficient in enzymatic hydrolysis of SECS at 3 to 12\% glucan loading. The optimal SSF conditions of SECS using a novel Saccharomyces cerevisiae were inoculation optical density $(\mathrm{OD})_{600}=4.0$, initial $\mathrm{pH} 4.8,50 \%$ nutrients added, 36 hours pre-hydrolysis time, $39^{\circ} \mathrm{C}$, and $12 \%$ glucan loading (20\% solid loading). With the addition of $2 \%$ Tween 20 , glucan conversion, ethanol yield, final ethanol concentration reached $78.6 \%, 77.2 \%$, and $59.8 \mathrm{~g} / \mathrm{L}$, respectively, under the optimal conditions. The results suggested that the solid and degradation products' inhibitory effect on the hydrolysis and fermentation of SECS were also not obvious at high glucan loading. Additionally, glucan conversion and final ethanol concentration in SSF of SECS increased by $13.6 \%$ and 18.7\%, respectively, compared with separate hydrolysis and fermentation (SHF).
\end{abstract}

Conclusions: Our research suggested that high glucan loading (6 to $12 \%$ glucan loading) and high temperature $\left(39^{\circ} \mathrm{C}\right)$ significantly improved the SSF performance of SECS using a thermal- and ethanol-tolerant strain of S. cerevisiae due to the removal of degradation products, sugar feedback, and solid's inhibitory effects. Furthermore, the surfactant addition obviously increased ethanol yield in SSF process of SECS.

Keywords: Corn stover biomass, High glucan loading, High temperature, Simultaneous saccharification and fermentation (SSF), Surfactant, Mass balance

\section{Background}

Environmental and economical sustainability benefits have increased the interests in alternative sources of energy $[1,2]$. Lignocellulosic ethanol (LCE) is considered as an important renewable alternative to fossil fuels due to the reduction of greenhouse gas emissions [3-5]. Corn stover

\footnotetext{
* Correspondence: bzli@tju.edu.cn

${ }^{1}$ Key Laboratory of Systems Bioengineering (Ministry of Education), Tianjin University, 92 Weijin Road, Nankai District, Tianjin 300072, China

${ }^{2}$ SynBio Research Platform, Collaborative Innovation Center of Chemical Science and Engineering (Tianjin), School of Chemical Engineering and Technology, Tianjin University, 92 Weijin Road, Nankai District, Tianjin 300072, China
}

\section{Biomed Central

(CS), which is the most abundant renewable resource, has been identified as one of the most promising feedstocks to produce LCE [6,7]. Generally, LCE production requires the following three major processes: pretreatment, enzymatic hydrolysis, and fermentation. Pretreatment is a necessary step for breaking down the lignin-carbohydrate complex (LCC) structures, which increases cellulose accessibility to enzymes in hydrolysis and improves ethanol yield in fermentation [8-10]. Due to the potentials for lowering environmental impact and lessening hazardous chemicals use, steam explosion pretreatment (SEP) is one of the most widely employed and efficient pretreatments for biomass refining $[4,11]$. SEP partially depolymerizes 
hemicellulose, relocates part of the lignin onto the surface of the biomass solid, and creates a large enzyme-accessible surface area $[12,13]$. Steam-exploded biomass was found to be highly digestible and highly fermentable, and it should be suitable for bio-based products refining [4,14,15].

Compared with separate hydrolysis and fermentation (SHF), simultaneous saccharification and fermentation (SSF) is usually preferred in LCE industry processes due to the low cost, the reduced contamination risk, and lower sugar inhibitory effects $[16,17]$. However, there are still several concerns about the SSF process, such as the optimum temperature discrepancies between saccharolytic enzymes and fermentation microbes [17]. In addition, one of the bottlenecks for commercialization of LCE refers to the low sugar concentration after enzymatic hydrolysis with associated low ethanol concentration in the fermentation broth [18-20]. From an economic feasibility standpoint, a high solid loading with satisfactory sugar and ethanol yields is required to reduce the cost of ethanol distillation in the downstream process of biomass refining. However, with the increase of solid loading in SSF, the concentration of inhibitors also increase, such as acetic acid, furfural, 5-hydroxymethyl furfural (HMF), and phenolic lignin degradation products (DPs) formed in pretreatment. High inhibitor concentrations may severely hamper the performance of the fermenting microorganism and, in the worst case scenario, result in a non-fermentable hydrolyzate [21-23]. Mass transfer is another inherent issue in SSF with high solid loading $[14,19]$. Therefore, in-depth investigation of the SSF process at high solid loading is helpful for commercialization of LCE.

In this study, two different biomass conversion processes, SHF and SSF, were investigated. Fermentation conditions that might affect the SSF performance (including inoculation optical density (OD), nutrients, initial $\mathrm{pH}$, and pre-hydrolysis time) were optimized. Both washed steam-exploded corn stover (SECS) and whole slurry (with all the inhibitors present) were used to evaluate the DPs' inhibitory effect in hydrolysis and fermentation process. Meanwhile, the SSF of SECS at high glucan loading was carried out using a novel yeast strain, thermal- and ethanol-tolerant Saccharomyces cerevisiae, and the surfactants (Tween 20, Tween 80, and bovine serum albumin (BSA)) were added to improve the fermentation performance. Mass balance around the whole process, including pretreatment, enzymatic hydrolysis, and fermentation, was performed to evaluate the CS biomass conversion performance.

\section{Results and discussion Enzymatic hydrolysis}

SEP was adopted to break down the structure of the lignocellulosic matrix to facilitate hydrolysis and fermentation.
Table 1 shows that SEP dissolved the most xylan and removed all the acetyl from untreated corn stover (UCS), which meant that the LCC structure of CS was disrupted. Although the lignin content increased, the glucan content of SECS increased by $86.1 \%$, compared with that of UCS. In general, the high glucan content was beneficial to the bioconversion process.

CS biomass pretreated by SE was subsequently hydrolyzed at 1 to $21 \%(\mathrm{w} / \mathrm{w})$ glucan loading, corresponding to 1.7 to $35.6 \%(\mathrm{w} / \mathrm{w})$ solid loading (Figure 1$)$. The results show that higher enzyme loading resulted in higher glucan conversion of either washed SECS (Figure 1A) or whole slurry (Figure 1B). The glucan conversion at 15 filter paper units (FPU)/g glucan was about 7 to $10 \%$ for washed SECS and 9 to $13 \%$ for whole slurry, respectively, lower than that at $60 \mathrm{FPU} / \mathrm{g}$ glucan, with the glucan loading varying from 1 to $15 \%$. However, the glucan conversion at 30 FPU/g glucan was only 2 to $4 \%$ for washed SECS and 1 to $5 \%$ for whole slurry, respectively, lower than that at 60 FPU/g glucan, with the glucan loading varying from 1 to $15 \%$. It should be noticed that glucan conversion was approximate at $18 \%$ and $21 \%$ glucan loading for all enzyme loadings, which indicated that the enzyme loading is not the main barrier for improving the enzymatic hydrolysis performance beyond $18 \%$ glucan loading. From an economic point of view, higher enzyme use should lead to higher cost of process. Actually, the enzyme accounts for a large proportion of the capital cost of industrial LCE production. Therefore, enzymatic hydrolysis of CS biomass should be the balance of the cost of enzyme and the hydrolysis performance.

The results also show that glucan conversion decreased with increasing glucan loading at all enzyme loadings (Figure 1A and 1B). But, it was interesting to note that the approximate glucan conversion was obtained for either washed SECS or whole slurry with glucan loading varying from 3 to $12 \%$ at all enzyme loadings. The previous study also reported that glucan conversion hardly changed with initial insoluble pretreated CS solids, varying from 2.5 to 25\% after 168 hours hydrolysis [24]. This phenomenon indicated that the poor mixture efficiency was not obvious

\begin{tabular}{|c|c|c|c|c|c|}
\hline \multicolumn{2}{|c|}{$\begin{array}{l}\text { UCS (\% of dry } \\
\text { weight) }\end{array}$} & \multicolumn{2}{|c|}{$\begin{array}{l}\text { SECS (\% of dry } \\
\text { weight) }\end{array}$} & \multicolumn{2}{|c|}{ DPs in SEL $(g / L)$} \\
\hline Glucan & $31.7(1.1)$ & Glucan & $59.0(1.2)$ & Formic acid & $2.3(0.2)$ \\
\hline Xylan & $17.1(0.7)$ & Xylan & $8.5(0.9)$ & Acetic acid & $2.7(0.3)$ \\
\hline Acetyl & $2.90(0.1)$ & Acetyl & 0 & HMF & $0.7(0.1)$ \\
\hline Lignin & $12.6(0.6)$ & Lignin & $23.1(1.5)$ & Furfural & $1.0(0.2)$ \\
\hline
\end{tabular}

DPs, Degradation products; HMF, 5-hydroxymethyl furfural; SECS, Steam-exploded corn stover; SEL, Steam-exploded liquor; UCS, Untreated corn stover. Standard deviations are shown in parentheses. 

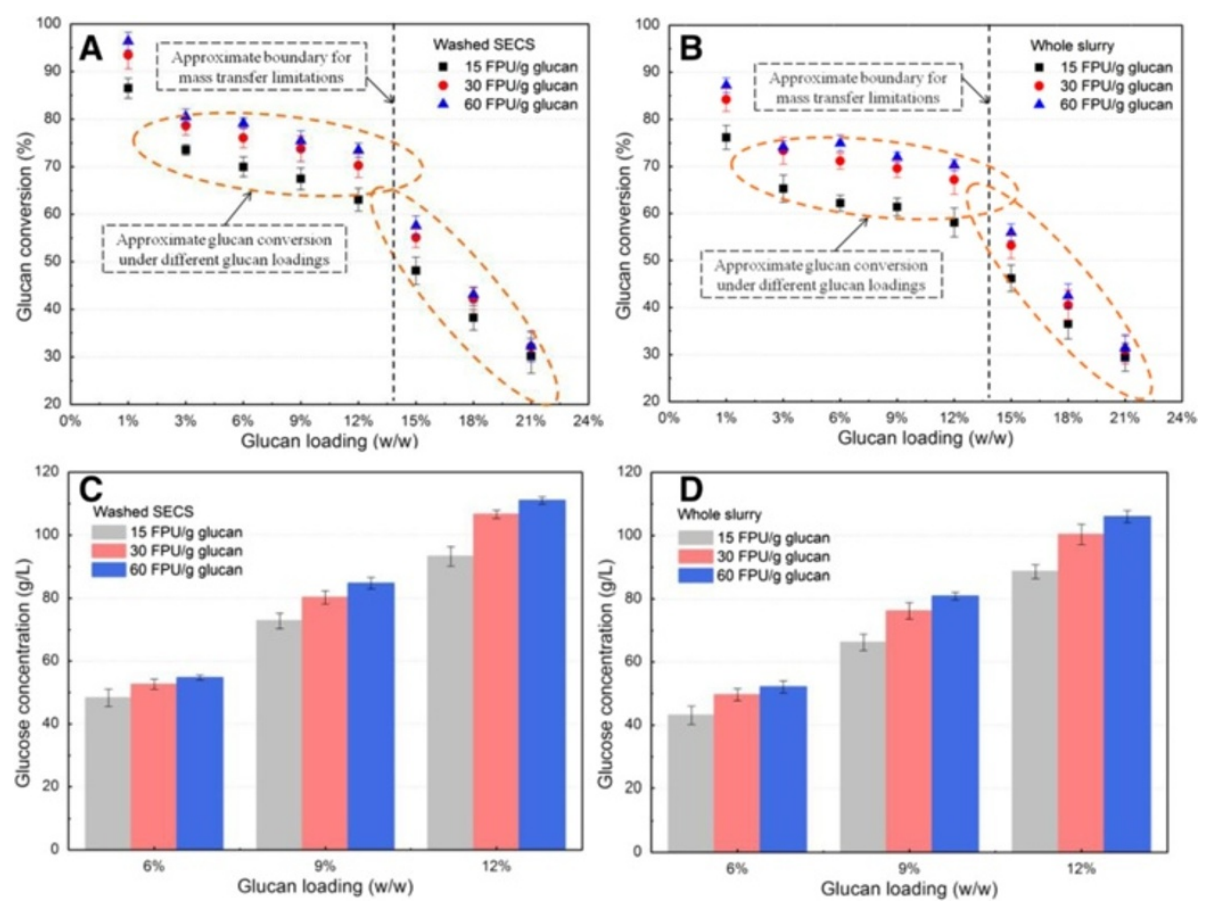

Figure 1 Enzymatic hydrolysis of washed SECS and whole slurry under different glucan loadings and enzyme loadings. Enzymatic hydrolysis conditions: $50^{\circ} \mathrm{C}, 200 \mathrm{rpm}$, and 168 hours. Glucan conversion of wash SECS (A) and whole slurry (B) and glucose concentration in enzymatic hydrolysis of wash SECS (C) and whole slurry (D) were determined. FPU, filter paper unit; SECS, steam-exploded corn stover.

in enzymatic hydrolysis of SECS at 3 to $12 \%$ glucan loading. Glucan conversion of washed SECS was maintained at approximately 63 to $70 \%$ at $15 \mathrm{FPU} / \mathrm{g}$ glucan, 71 to $79 \%$ at $30 \mathrm{FPU} / \mathrm{g}$ glucan, and 74 to $82 \%$ at $60 \mathrm{FPU} / \mathrm{g}$ glucan, with glucan loading varying from 3 to $12 \%$. However, glucan conversion of SECS was not more than $83 \%$ at 3 to $12 \%$ glucan loading, with an enzyme loading of $60 \mathrm{FPU} / \mathrm{g}$ glucan. This upper limit was likely due to the steric obstruction of glucan by other components in SECS, such as recondensed lignin and retained xylan $[24,25]$. Another interesting result from this data was that glucan conversion obviously decreased from about 60 to $30 \%$ for both washed SECS and whole slurry with glucan loading increasing from 15 to $21 \%$. The one reason for this result may be that sugar concentration was rapidly increased when glucan loading was more than $15 \%$, and hence the products' feedback (sugar) inhibitory effect on enzymes should be strengthened $[18,19]$. Another reason is that the slurry's rheological property was changed, and convective diffusion was turned into molecular diffusion, hence the boundary for mass transfer limitations may have been reached, due to the solid's effects $[19,20]$.

Figure $1 \mathrm{~A}$ and $1 \mathrm{~B}$ also shows that the DPs' inhibitory effect on enzymatic hydrolysis decreased with the increase of glucan loading. Glucan conversion of whole slurry decreased by 6 to $9 \%$ at $15 \mathrm{FPU} / \mathrm{g}$ glucan and 3 to $5 \%$ at $30 \mathrm{FPU} / \mathrm{g}$ glucan and $60 \mathrm{FPU} / \mathrm{g}$ glucan, respectively, with glucan loading increasing from 3 to $12 \%$, compared with that of washed SECS. This results suggested that the DPs' inhibitory effect was obvious for low enzyme loading. However, glucan conversion of whole slurry decreased by only 1 to $2 \%$ at all enzyme loadings, with glucan loading increasing from 15 to $21 \%$, compared with that of washed SECS. The reason for this result may be that the mass transfer limitations should be the major problem when the glucan loading is beyond $15 \%$. These results suggested that the DPs' inhibitory effect was mild in enzymatic hydrolysis of SECS with an enzyme loading of $30 \mathrm{FPU} / \mathrm{g}$ and $60 \mathrm{FPU} / \mathrm{g}$ glucan, especially at high glucan loading.

The ethanol concentration in the broth entering the distillation should be above $40 \mathrm{~g} / \mathrm{L}$ in order to make an economical feasible process for industrial bioethanol production $[18,25,26]$, which means that glucose concentration should be more than $80 \mathrm{~g} / \mathrm{L}$. Figure $1 \mathrm{C}$ and 1D show that glucose concentration reached $106.6 \mathrm{~g} / \mathrm{L}$ for washed SECS and $100.3 \mathrm{~g} / \mathrm{L}$ for whole slurry at 30 FPU/g glucan, and $111.2 \mathrm{~g} / \mathrm{L}$ for washed SECS and $106.1 \mathrm{~g} / \mathrm{L}$ for whole slurry at $60 \mathrm{FPU} / \mathrm{g}$ glucan, for $12 \%$ glucan loading hydrolysis. Enzymatic hydrolysis at high glucan loadings also saves production time and equipments and improved the production productivity, and hence decreases the capital cost of process compared with that at low- or moderate-glucan loadings. Therefore, SECS 
can be considered as one of the best biomasses available for bioethanol production at high glucan loading due to the small difference in glucan conversion among 6\% and $12 \%$ glucan loading, the satisfied sugar concentration, and the low DPs' inhibitory effect.

\section{Optimization of simultaneous saccharification and fermentation conditions}

The SSF of washed SECS and whole slurry under different conditions, including inoculation OD, nutrients, initial $\mathrm{pH}$, and pre-hydrolysis time, were performed at $6 \%$ glucan loading (Table 2), and the results are given in Figures 2 and 3.

The larger inoculation OD should certainly have helped to initiate the SSF process, but it resulted in the higher capital cost of seed preparation. Therefore, the optimal experiments were carried out at $36^{\circ} \mathrm{C}$ with $50 \%$ nutrients, initial $\mathrm{pH} 4.8$, and 36 hours pre-hydrolysis to balance the cost of seed preparation and the influences of inoculation OD on the SSF performance. The results show that ethanol concentration rapidly increased at the first 6 hours under different inoculation OD, and the initial ethanol yield increased according to the order of $\mathrm{OD}_{600}=4.0$, followed by $\mathrm{OD}_{600}=8.0$, followed by $\mathrm{OD}_{600}=1.0$, for both washed SECS and whole slurry (Figure 2A and 2B). Final ethanol concentration (168 hours) displayed a similar trend in SSF, which indicated that the excessive low or high inoculation OD was adverse for SSF. The possible reason for the poor SSF performance with low inoculation OD could be that the yeast cell viability was inhibited by the solid's inhibitory effect due to the binding of the yeast cells to the fermentation solid residues [27,28]. Figure 3A and $3 \mathrm{~B}$ shows that the cell viability (colony forming unit $(\mathrm{CFU}))$ at $\mathrm{OD}_{600}=1.0$ was lowest, which slightly increased before 12 hours and then decreased, with fermentation time varying from 24 to 168 hours, which agrees with the above analysis. As for high inoculation OD, the excessive high OD should consume more glucose and convert nutrition into the microbial biomass, resulting in low ethanol productivity. Figure 3A and 3B shows that the cell viability $(\mathrm{CFU})$ at $\mathrm{OD}_{600}=8.0$ was highest, which supports the above analysis. In addition, the cell viability (CFU) at $\mathrm{OD}_{600}=8.0$ decreased by $82 \%$ for washed SECS and $75 \%$ for whole slurry at 168 hours. These results suggest that, besides the solid's inhibitory effect, the exhaustion of nutrition should also restrict the growth of yeast at the late stage of fermentation. Therefore, combined with the analysis of initial ethanol yield, final ethanol concentration, and cell viability, the optimal inoculation OD was determined as 4.0 in SSF.

The ethanol production efficiency by $S$. cerevisiae was strongly affected by the nitrogen source in the medium in SSF $[29,30]$. Effect of nutrients on the SSF performance was carried out (Figure $2 \mathrm{C}$ and $2 \mathrm{D}$ ). It is interesting to note that nutrients were not added under $0 \%$ nutrients (N) in SSF, but cell viability (CFU) slowly increased before 24-hour fermentation (Figure $3 \mathrm{C}$ and $3 \mathrm{D}$ ), and glucose was still converted into ethanol with fermentation progression. This may be due to the fact that CS contained nutrients (such as protein and inorganic nitrogen), which were beneficial to yeast growth. It was clear that an initial ethanol yield under $50 \% \mathrm{~N}$ increased by $19.8 \%$ for washed SECS, and $13.7 \%$ for whole slurry, compared with that under $0 \% \mathrm{~N}$ (Figure 2C and 2D). Final ethanol concentration (168 hours) under $50 \% \mathrm{~N}$ increased by $8.7 \%$ for SECS, and $10.6 \%$ for whole slurry, compared with that under $0 \%$ N. Meanwhile, cell viability (CFU) under $50 \% \mathrm{~N}$ was 1.2 to 1.4 times for SECS and 1.1 to 1.2 times for whole slurry than that under $0 \% \mathrm{~N}$. Although the nutrients concentration increased from 50 to $100 \% \mathrm{~N}$, ethanol concentration (Figure $2 \mathrm{C}$ and $2 \mathrm{D}$ ) and cell viability (CFU) (Figure $3 \mathrm{C}$ and 3D) did not increase further. The reason for this result may be that high nutrients contained high salt concentration in high glucan loading fermentation broth, which may have inhibited cell viability and thereby reduce the SSF performance [31,32]. In addition, the high nutrients addition should also increase the costs of SSF. Therefore, results suggested that $50 \% \mathrm{~N}$ addition should meet the requirements of SSF.

Initial $\mathrm{pH}$ is one of most important parameters for enzyme activity and cell viability in SSF [31,33]. Figure $2 \mathrm{E}$ and $2 \mathrm{~F}$ shows that the highest initial ethanol yield was obtained at initial $\mathrm{pH} 4.8$, which, at initial $\mathrm{pH}$ values of 4.0 and 5.5, was 1.41 times and 1.31 times that for SECS and 1.24 times and 1.08 times that for whole slurry,

Table 2 Experiment design for the effects of inoculation OD, nutrients, initial pH, pre-hydrolysis time, and temperature on the SSF performance of washed SECS and whole slurry by Saccharomyces cerevisiae

\begin{tabular}{llllll}
\hline Parameter & Effect of OD & Effect of nutrients & Effect of initial pH & Effect of pre-hydrolysis time & Effect of temperature \\
\hline Initial $\mathrm{OD}_{600}$ & $1.0,4.0,8.0$ & 4.0 & 4.0 & 4.0 & 4.0 \\
Nutrients & $50 \%$ & $0 \%, 50 \%, 100 \%$ & $50 \%$ & $50 \%$ & $50 \%$ \\
Initial pH & 4.8 & 4.8 & $4.0,4.8,5.5$ & 4.8 & 4.8 \\
Pre-hydrolysis time (hours) & 36 & 36 & 36 & $24,36,48$ & 36 \\
Temperature $\left({ }^{\circ} \mathrm{C}\right)$ & 36 & 36 & 36 & 36 & $30,33,36,39,42$ \\
\hline
\end{tabular}

$100 \%$ nutrients was defined as $10 \mathrm{~g} / \mathrm{L}$ yeast extract and $20 \mathrm{~g} / \mathrm{L}$ peptone; $50 \%$ nutrients was defined as $5 \mathrm{~g} / \mathrm{L}$ yeast extract and $10 \mathrm{~g} / \mathrm{L}$ peptone; $0 \%$ nutrients was defined as $0 \mathrm{~g} / \mathrm{L}$ yeast extract and $0 \mathrm{~g} / \mathrm{L}$ peptone. OD, optical density; SSF, simultaneous saccharification and fermentation; SECS, steam-exploded corn stover. 

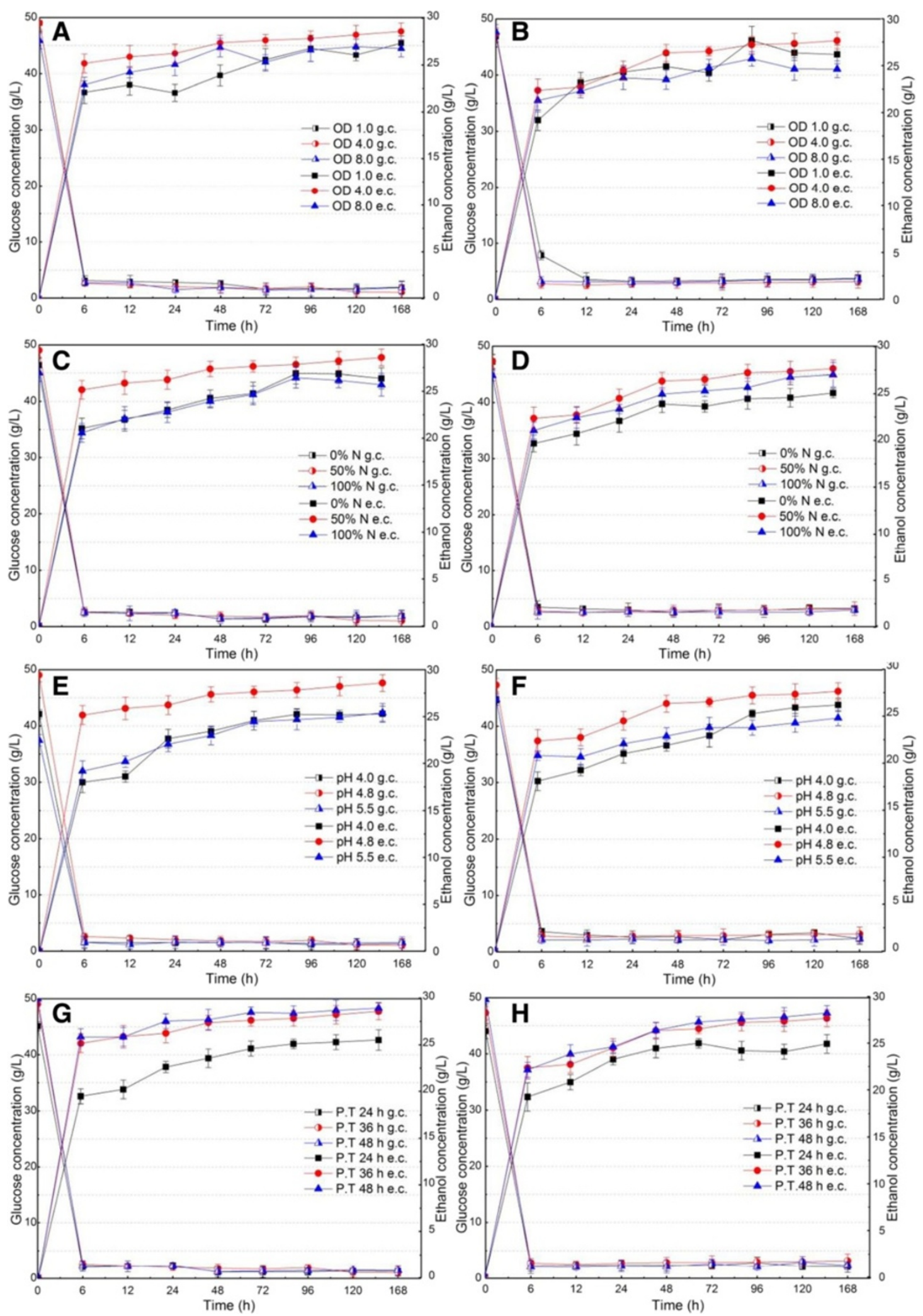

Figure 2 (See legend on next page.) 
(See figure on previous page.)

Figure 2 Effects of inoculation OD ( $A$ and $B)$, nutrients ( $C$ and $D)$, initial pH (E and F), and pre-hydrolysis time (G and $H)$ on the SSF performance of washed steam-exploded corn stover (A, C, E, and G) and whole slurry (B, D, F, and H). e.C., ethanol concentration; g.C., glucose concentration; CFU, colony forming unit; N, nutrients; OD, optical density; P.T., pre-hydrolysis time; SECS, steam-exploded corn stover; WS, whole slurry.

respectively. The highest final ethanol concentration was also obtained at initial $\mathrm{pH} 4.8$, which was $28.6 \mathrm{~g} / \mathrm{L}$ for SECS and $27.6 \mathrm{~g} / \mathrm{L}$ for whole slurry. It is interesting to note that the highest cell viability was obtained at initial $\mathrm{pH}$ 5.5, followed by initial $\mathrm{pH} 4.8$ and initial $\mathrm{pH} 4.0$ (Figure 3E and 3F). Previous studies had reported that $S$. cerevisiae increased ethanol production at $\mathrm{pH} 5.0$ and 5.5 as opposed to $\mathrm{pH} 4.0$ and 4.5 , and its optimum $\mathrm{pH}$ was from 5.0 to 5.2 [33]. Therefore, judging from the initial ethanol yield and final ethanol concentration, initial $\mathrm{pH} 4.8$ was the optimum $\mathrm{pH}$ for SSF among the tested values.

Pre-hydrolysis time directly influenced the content and composition of unhydrolyzed solids, as well as the composition of hydrolysate in SSF, due to the different temperature between hydrolysis and fermentation [26,27,34]. The purpose of pre-hydrolysis of SECS in SSF was to hydrolyze the solid quickly at a high temperature so that a more homogenous and a higher glucose concentration hydrolysate could be formed for subsequent ethanol fermentation. In addition, pre-hydrolysis resulted in the low initial viscosity of fermentation broth due to the hydrolysis of the pretreated solid, so diffusion and mixing limitations could be minimized or altogether avoided during fermentation. The results show that glucose concentrations after 24, 36, and 48 hours pre-hydrolysis were $45.1,49.0$, and $51.3 \mathrm{~g} / \mathrm{L}$ for SECS and 43.8, 47.1, and $49.6 \mathrm{~g} / \mathrm{L}$ for whole slurry, respectively (Figure $2 \mathrm{G}$ and $2 \mathrm{H}$ ). It was clearly observed that the order effects of pre-hydrolysis time on initial ethanol yield and final ethanol concentration were 48 hours, followed by 36 hours, followed by 24 hours. The yeast cell viabilities were also obviously enhanced with the increase of pre-hydrolysis time due to the fact that the increased initial glucose concentration provided more nutrients (Figure $3 \mathrm{G}$ and $3 \mathrm{H}$ ). However, it should be noted that the SSF performance for 36 hours was almost similar to that for 48 hours, and the increase of pre-hydrolysis time may obviously increase the sugar's inhibitory effect and reduce the utilization efficiency of equipments. Therefore, the optimum pre-hydrolysis time was determined as 36 hours in SSF.

DPs formed by pretreatment (such as carboxylic acids, phenols, and furans) were considered as the potential inhibitors in high glucan loading fermentation [18,20,35]. DPs' concentrations in steam-exploded liquor (SEL) were $2.3 \mathrm{~g} / \mathrm{L}$ formic acid, $2.7 \mathrm{~g} / \mathrm{L}$ acetic acid, $0.7 \mathrm{~g} / \mathrm{L} \mathrm{HMF}$, and $1.0 \mathrm{~g} / \mathrm{L}$ furfural (Table 1). In this study, a novel S. cerevisiae which can tolerate $5.3 \mathrm{~g} / \mathrm{L}$ acetic acid, $1.3 \mathrm{~g} / \mathrm{L}$ furfural, and $0.5 \mathrm{~g} / \mathrm{L}$ phenol [36], was used to reduce the DPs' inhibitory effect. The results implied that initial ethanol yields of whole slurry (Figure 2B, 2D, 2F and $2 \mathrm{H}$ ) were 5 to $15 \%$ lower than that of SECS (Figure 2A, 2C, 2E and $2 \mathrm{G}$ ), but it was clearly observed that ethanol concentration of whole slurry was approximate to that of SECS after 48 hours fermentation under the same fermentation conditions. Figure 3 show that approximately the highest cell viability was obtained at 12 hours for SECS (Figure 3A, $3 \mathrm{C}, 3 \mathrm{E}$ and $3 \mathrm{G}$ ) and at 24 hours for whole slurry (Figure 3B, 3D, 3F and 3H) in SSF. However, cell viability (CFU) for whole slurry was approximate to that for SECS, with fermentation progression. Therefore, the results suggest that the DPs' concentration appears to be too low to impair the fermentation performance, indicating that thermal- and ethanol-tolerant S. cerevisiae had good fermentability of either washed SECS or whole slurry.

The products' (sugar) feedback inhibitory effect was also a major problem for the traditional SHF process. In the SSF process, the increase of viability (CFU) was observed in the first 12 hours fermentation for SECS and 24 hours fermentation for whole slurry (Figure 3), due to the high initial glucose concentration (Figure 2). Glucose was still being released after 24 hours fermentation, but the cell viabilities began to decrease. The possible reason for this result may be that the glucose release rate was too slow to satisfy the demand of yeast cell growth. Glucose concentration was less than $2.0 \mathrm{~g} / \mathrm{L}$ for SECS and $3.0 \mathrm{~g} / \mathrm{L}$ for whole slurry after 6 hours fermentation, but ethanol concentration still increased with fermentation progression, which indicated that the sugar's inhibitory effect should be removed in SSF at high glucan loading.

\section{Effects of temperature on the simultaneous saccharification and fermentation performance}

Traditional SSF (conducted at $30^{\circ} \mathrm{C}$ ) shortened the overall process time by combining hydrolysis and ethanol fermentation, and hence had a higher productivity than SHF. However, the low processing temperature limited the sugar conversion and hence limited the further improvement of ethanol productivity in SSF [17,27]. In general, the increase of temperature increased sugar conversion and the increase of ethanol concentration decreased sugar conversion in the traditional SSF process. The ideal temperature is approximately $30^{\circ} \mathrm{C}$ for most $S$. cerevisiae strains and $50^{\circ} \mathrm{C}$ for cellulases. A higher temperature should stress $S$. cerevisiae and make them more susceptible to 

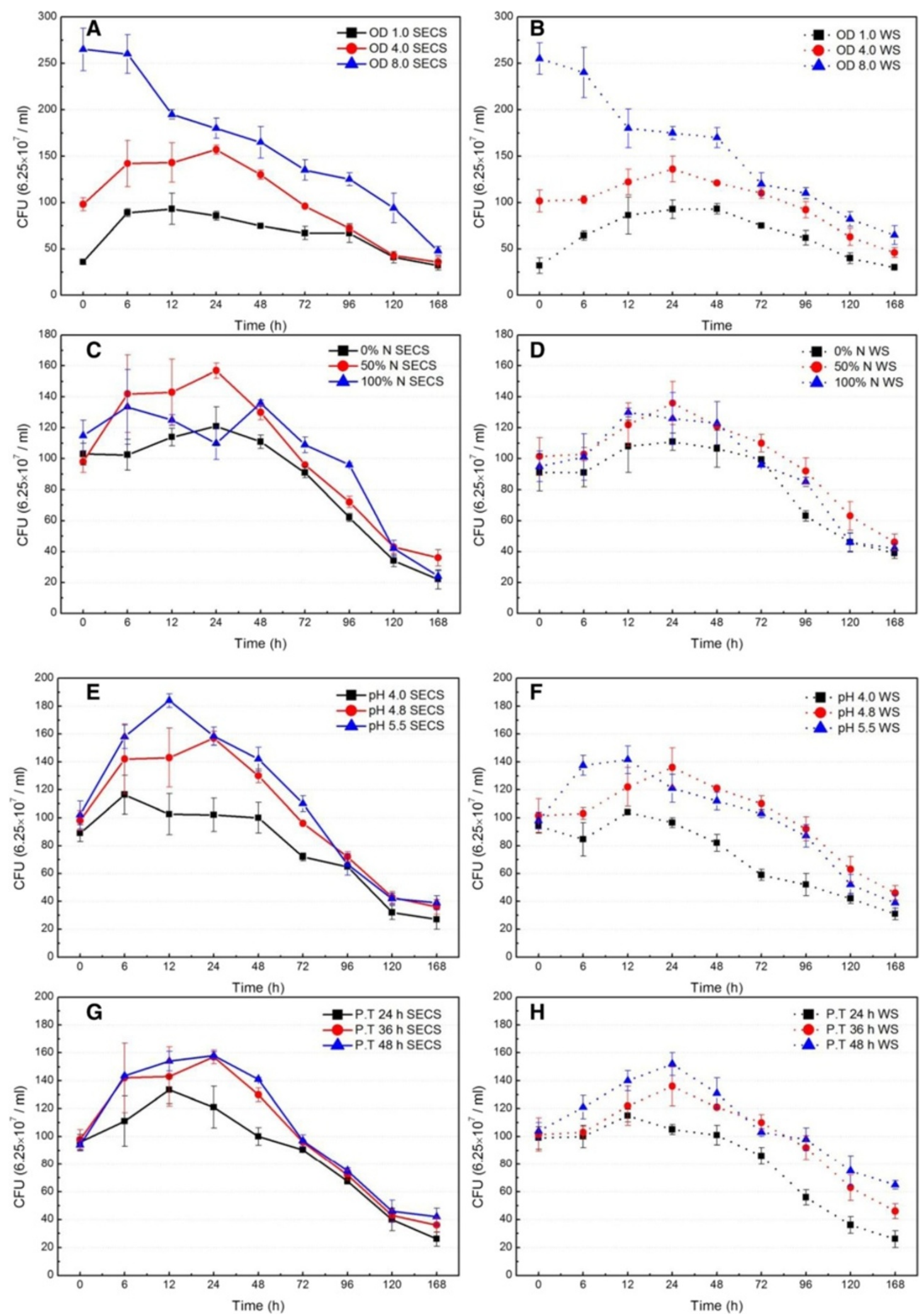

Figure $\mathbf{3}$ (See legend on next page.) 
(See figure on previous page.)

Figure 3 Effects of inoculation OD ( $A$ and $B$ ), nutrients ( $C$ and $D)$, initial pH (E and F), and pre-hydrolysis time (G and $H$ ) on cell viability (colony forming unit) in simultaneous saccharification and fermentation of washed steam-exploded corn stover ( $\mathrm{A}$, $\mathrm{C}$, $\mathrm{E}$, and $\mathrm{G})$ and whole slurry (B, D, F, and H). CFU, colony forming unit; N, nutrients; OD, optical density; P.T., pre-hydrolysis time; SECS, steam-exploded corn stover; WS, Whole slurry.

other stresses such as ethanol, especially at ethanol concentration beyond $30 \mathrm{~g} / \mathrm{L}$ [33,37]. Therefore, thermal- and ethanol-tolerant yeast strains for improving ethanol productivity are required to fully exploit the merits of the SSF process.

Thermal- and ethanol-tolerant $S$. cerevisiae, which can tolerate up to $42^{\circ} \mathrm{C}$ and $6 \%(\mathrm{w} / \mathrm{v})$ ethanol, was used in SSF of SECS at inoculation OD 4.0, initial pH 4.8, 50\% nutrients, 36 hours pre-hydrolysis time, and 6\% glucan loading (Figure 4). The results show that glucose concentration at 6 hours fermentation was less than $1.0 \mathrm{~g} / \mathrm{L}$ at $30^{\circ} \mathrm{C}$ and $33^{\circ} \mathrm{C}$, and approximate $2.0 \mathrm{~g} / \mathrm{L}$ at $36^{\circ} \mathrm{C}$ and $39^{\circ} \mathrm{C}$, while it was about $3.0 \mathrm{~g} / \mathrm{L}$ at $42^{\circ} \mathrm{C}$ (Figure $4 \mathrm{~A}$ ). It indicated that glucose concentration was maintained at a low level in SSF, which obviously reduced the products' feedback inhibitory effect. It is interesting to note that ethanol concentration increased by $12.6 \%$ for $30^{\circ} \mathrm{C}, 15.8 \%$ for $33^{\circ} \mathrm{C}, 15.0 \%$ for $36^{\circ} \mathrm{C}, 22.5 \%$ for $39^{\circ} \mathrm{C}$, and $33.7 \%$ for $42^{\circ} \mathrm{C}$, with fermentation time increasing from 6 to 168 hours (Figure 4B). Compared with that for $30^{\circ} \mathrm{C}$ (traditional SSF), initial ethanol yield increased by $1.0 \%$ for $33^{\circ} \mathrm{C}, 5.9 \%$ for $36^{\circ} \mathrm{C}, 14.3 \%$ for $39^{\circ} \mathrm{C}$, and $1.7 \%$ for $42^{\circ} \mathrm{C}$ at 6 hours, and final ethanol concentration increased by $6.4 \%, 10.6 \%$, $27.8 \%$, and $22.7 \%$, respectively. It should be noted that ethanol concentration hardly changed at $42^{\circ} \mathrm{C}$ with fermentation time varying from 6 to 24 hours, and then rapidly increased with an increase of fermentation time. The reason for this result may be that $S$. cerevisiae adapts to the high temperature environment at the beginning of fermentation. The maximal initial ethanol yield and final ethanol concentration were obtained at $39^{\circ} \mathrm{C}$. These results indicated that the SSF performance of SECS was improved with the temperature increasing from $30^{\circ} \mathrm{C}$ to $39^{\circ} \mathrm{C}$ using thermal- and ethanol-tolerant S. cerevisiae. Therefore, the optimal $39^{\circ} \mathrm{C}$ was a chosen as a compromise for increasing the activity of cellulase and allowing $S$. cerevisiae to still ferment sugars in SSF.

By-products of fermentation were the major factor for evaluating SSF performance. Effects of fermentation conditions on by-products (glycerol and acetic acid) in SSF of washed SECS and whole slurry were carried out, and the results are given in Table 3 . The glycerol concentration varied from 0.84 to $1.64 \mathrm{~g} / \mathrm{L}$ for washed SECS, while the acetic acid concentration varied from 1.94 to $3.21 \mathrm{~g} / \mathrm{L}$ under different SSF conditions. It is interesting to note that the glycerol concentration varied from 1.23 to $1.87 \mathrm{~g} /$ $\mathrm{L}$ for whole slurry, and the acetic acid concentration varied from 3.01 to $4.52 \mathrm{~g} / \mathrm{L}$ under different SSF conditions, which increased by 5.6 to $19.8 \%$ and 20.6 to $65.1 \%$ compared with that for SECS, respectively. The possible reason for these results should be that whole slurry contained the DPs formed in pretreatment, which enhanced the secondary metabolism of S. cerevisiae. Furthermore, the acetic acid generated from pretreatment increased the final acetic acid concentration in SSF of whole slurry. However, the ethanol concentration for whole slurry decreased by only 2 to $4 \%$, compared with that for washed SECS. These results indicated that the thermal- and ethanol-tolerant S. cerevisiae had the good fermentability of washed SECS and whole slurry in SSF at high temperature.
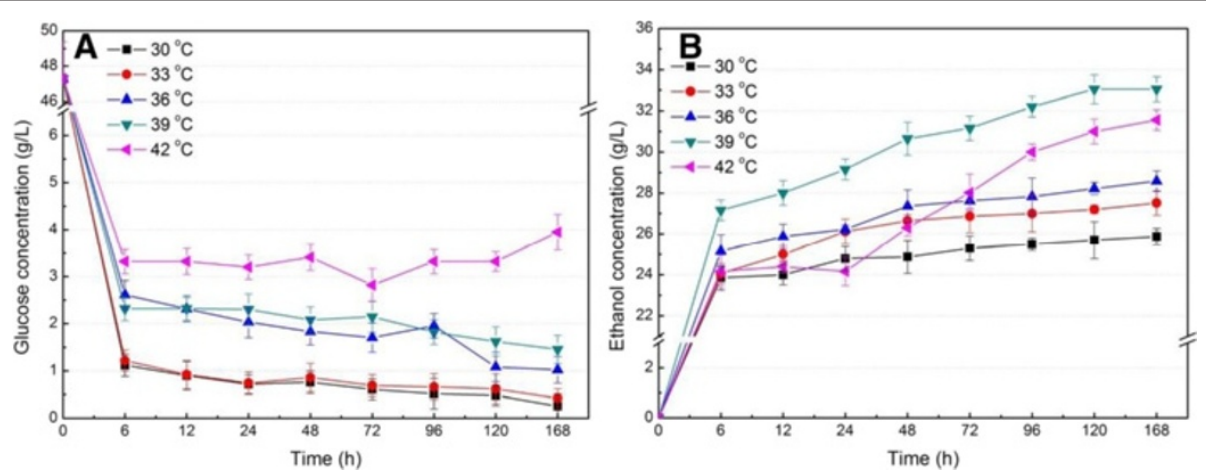

Figure 4 Simultaneous saccharification and fermentation performances of steam-exploded corn stover at different temperatures.

Glucose (A) and ethanol (B) concentration were determined in SSF at different temperatures. The experiments were conducted at inoculation OD 4.0, $\mathrm{pH} 4.8,50 \%$ nutrients, 36 hours pre-hydrolysis time, and 6\% glucan loading. OD, optical density; SSF, simultaneous saccharification and fermentation. 
Table 3 Effects of inoculation OD, nutrients, initial pH, pre-hydrolysis time, and temperature on glycerol, acetic acid, and ethanol production in the SSF process of washed SECS and whole slurry by Saccharomyces cerevisiae

\begin{tabular}{|c|c|c|c|c|c|c|}
\hline \multirow[b]{2}{*}{ Experimental parameters } & \multicolumn{3}{|l|}{ Washed SECS } & \multicolumn{3}{|c|}{ Whole slurry (SECS + SEL) } \\
\hline & Glycerol (g/L) & Acetic acid (g/L) & Ethanol (g/L) & Glycerol (g/L) & Acetic acid (g/L) & Ethanol (g/L) \\
\hline \multicolumn{7}{|l|}{ Initial $\mathrm{OD}_{600}$} \\
\hline 1.0 & $1.21(0.04)$ & $2.34(0.08)$ & $27.3(0.7)$ & $1.45(0.06)$ & $3.01(0.09)$ & $26.2(0.7)$ \\
\hline 4.0 & $1.25(0.04)$ & $2.72(0.06)$ & $28.6(0.8)$ & $1.37(0.05)$ & $3.56(0.08)$ & $27.7(0.9)$ \\
\hline 8.0 & $1.51(0.06)$ & $2.83(0.04)$ & $26.7(0.8)$ & $1.74(0.04)$ & $4.28(0.04)$ & $24.6(0.8)$ \\
\hline \multicolumn{7}{|l|}{ Nutrients } \\
\hline $0 \%$ & $1.17(0.05)$ & $1.96(0.05)$ & $26.4(0.6)$ & $1.29(0.04)$ & $3.05(0.05)$ & $27.1(0.6)$ \\
\hline $50 \%$ & $1.25(0.04)$ & $2.72(0.06)$ & $28.6(0.8)$ & $1.37(0.05)$ & $3.56(0.08)$ & $27.7(0.9)$ \\
\hline $100 \%$ & $1.62(0.03)$ & $2.48(0.09)$ & $25.7(1.1)$ & $1.91(0.04)$ & $4.34(0.07)$ & $25.1(1.0)$ \\
\hline \multicolumn{7}{|l|}{ Initial pH } \\
\hline 4.0 & $0.84(0.07)$ & $1.94(0.05)$ & $25.3(0.3)$ & $1.32(0.07)$ & $3.03(0.06)$ & $26.2(0.6)$ \\
\hline 4.8 & $1.25(0.04)$ & $2.72(0.06)$ & $28.6(0.8)$ & $1.37(0.05)$ & $3.56(0.08)$ & $27.7(0.9)$ \\
\hline 5.5 & $1.61(0.03)$ & $2.86(0.08)$ & $25.4(0.7)$ & $1.87(0.08)$ & $4.01(0.09)$ & $24.8(1.2)$ \\
\hline \multicolumn{7}{|l|}{ Effects of pre-hydrolysis time } \\
\hline 24 hours & $1.08(0.06)$ & $2.77(0.09)$ & $25.5(0.7)$ & $1.23(0.07)$ & $3.64(0.06)$ & $24.9(0.7)$ \\
\hline 36 hours & $1.25(0.04)$ & $2.72(0.06)$ & $28.6(0.8)$ & $1.37(0.05)$ & $3.56(0.08)$ & $27.7(0.9)$ \\
\hline 48 hours & $1.56(0.04)$ & $2.32(0.05)$ & $27.6(0.5)$ & $1.71(0.04)$ & $3.34(0.05)$ & $25.9(0.6)$ \\
\hline \multicolumn{7}{|l|}{ Effects of temperature } \\
\hline $30^{\circ} \mathrm{C}$ & $1.12(0.06)$ & $3.01(0.08)$ & $25.8(0.8)$ & $1.23(0.03)$ & $4.28(0.09)$ & $24.9(0.4)$ \\
\hline $33^{\circ} \mathrm{C}$ & $1.31(0.04)$ & $3.21(0.06)$ & $27.5(1.2)$ & $1.46(0.06)$ & $4.52(0.06)$ & $26.5(0.5)$ \\
\hline $36^{\circ} \mathrm{C}$ & $1.25(0.04)$ & $2.72(0.03)$ & $28.6(0.8)$ & $1.37(0.05)$ & $3.56(0.08)$ & $27.7(0.9)$ \\
\hline $39^{\circ} \mathrm{C}$ & $1.64(0.07)$ & $2.52(0.06)$ & $33.1(0.6)$ & $1.73(0.07)$ & $3.04(0.07)$ & $32.1(0.8)$ \\
\hline $42^{\circ} \mathrm{C}$ & $1.55(0.03)$ & $2.24(0.07)$ & $31.5(1.3)$ & $1.69(0.09)$ & $3.01(0.05)$ & $30.2(1.0)$ \\
\hline
\end{tabular}

Standard deviations are shown in parentheses. OD, optical density; SECS, steam-exploded corn stover; SEL, steam-exploded liquor; SSF, simultaneous saccharification and fermentation.

Effects of glucan loading on the simultaneous saccharification and fermentation performance

An important factor in the process economics and energy balance is the concentration of glucan loadings in the stream entering the hydrolysis and fermentation step $[9,19,24]$. By increasing glucan loading, the resulting sugar concentration and, consequently, final ethanol concentration will be higher. This has a significant effect on production cost due to the reduced size of equipment (tanks and distillation column, and so forth) and the reduced energy utilization for distillation $[18,20]$. Effects of glucan loading (3 to $15 \%$ glucan loading, corresponding to 5.0 to $25.4 \%$ solid loading) on the SSF performance of SECS at optimized conditions were carried out. The results show that $3 \%$ glucan loading showed the highest glucan conversion (Figure 5A), xylan conversion (Figure 5B), and ethanol yield (Figure 5D), but it also obtained the lowest ethanol concentration (Figure 5C). With glucan loading increasing from 6 to 12\%, glucan conversion, xylan conversion, and ethanol yield reduced less than 5.6\%, 8.0\%, and 5.2\%, respectively, compared with that at $3 \%$ glucan loading.
Ethanol concentration increased from 30.2 to $55.4 \mathrm{~g} / \mathrm{L}$ when glucan loading increased from 6 to $12 \%$, and the relative ethanol concentration increased by $83.4 \%$.

Previous research has stated that the most economical ethanol distillation process should be achieved when the ethanol concentration was more than $4 \%(w / w)[18,19,25]$. Ethanol concentration reached 45.2 and $55.4 \mathrm{~g} / \mathrm{L}$ at $9 \%$ and $12 \%$ glucan loading (Figure $5 \mathrm{C}$ ), respectively, with high glucan conversion and ethanol yield, which implied that SSF of SECS at high glucan loading and high temperature should meet the requirements of ethanol industrial production. It should be noticed that although ethanol concentration was approximate to that at $12 \%$ glucan loading, glucan conversion, xylan conversion, and ethanol yield rapidly decreased at $15 \%$ glucan loading (25.4\% solid loading) (Figure 5). The possible reason for this phenomenon may be that the increased solid content increased the viscosity of the mixture and hence reduced the mixing efficiency, leading to poor mass and heat transfer in SSF $[18,19,38]$. The results suggested that the approximate boundary of mass transfer limitations for the 

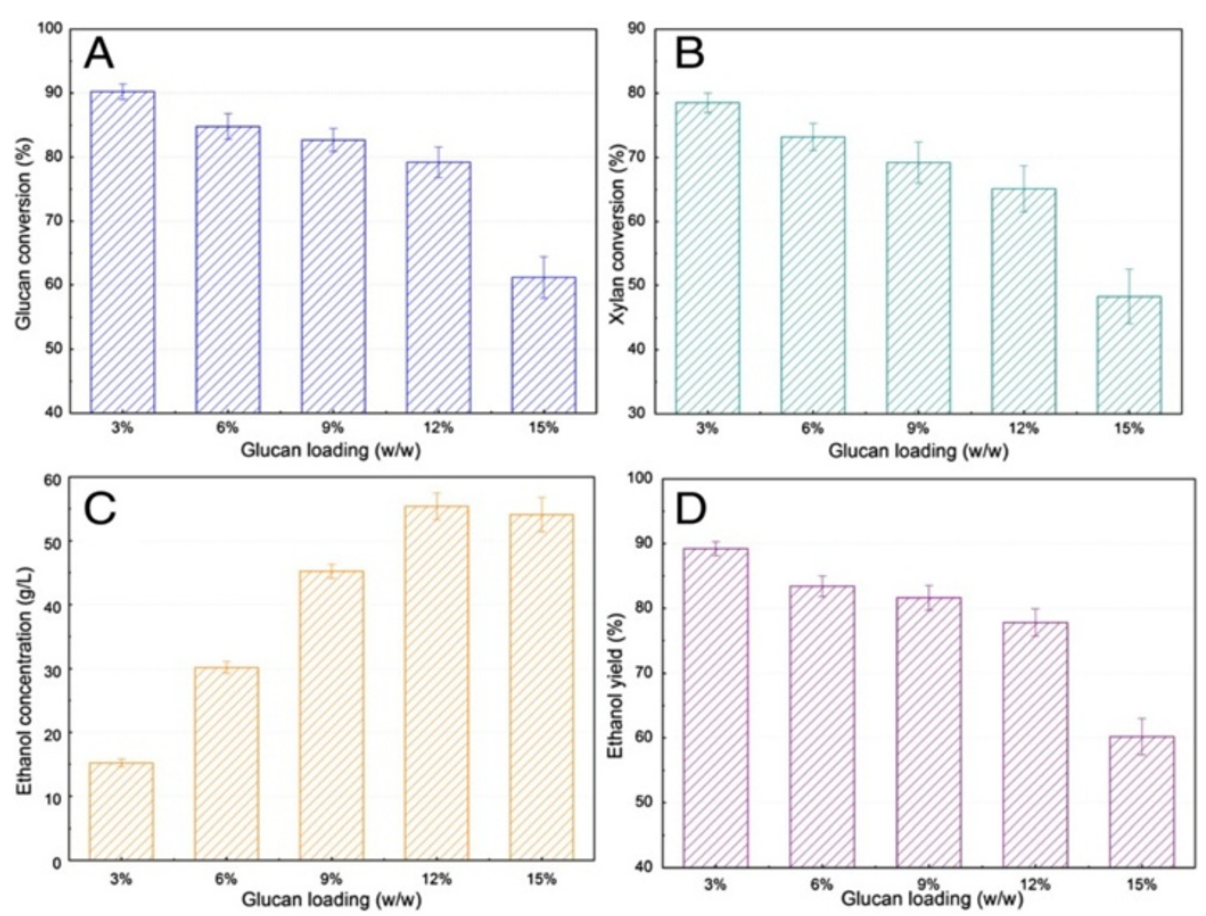

Figure 5 Simultaneous saccharification and fermentation performances of steam-exploded corn stover at different glucan loadings. Glucan conversion (A), xylan conversion (B), ethanol concentration (C), and ethanol yield (D) were determined in SSF. The experiments were conducted at inoculation $\mathrm{OD} 4.0, \mathrm{pH} 4.8,39^{\circ} \mathrm{C}, 50 \%$ nutrients, and 36 hours pre-hydrolysis time. OD, optical density; SSF, simultaneous saccharification and fermentation.

SSF of SECS was about between $12 \%$ and $15 \%$ glucan loading, corresponding to $20.3 \%$ and $25.4 \%$ solid loading. Therefore, $9 \%$ and $12 \%$ glucan loading should be the suitable conditions for converting SECS to ethanol in SSF.

\section{Effects of surfactants on performance of simultaneous saccharification and fermentation}

Surfactants have been proven to be effective in enhancing enzymatic hydrolysis of cellulose [39-41], but the effects of surfactants on the SSF of SECS to ethanol at high glucan loading is not well understood. We explored the effects of the surfactants Tween 20, Tween 80, and BSA as an additive on the SSF performance at $6 \%$ and $9 \%$ glucan loading, corresponding to $10.2 \%$ and $15.3 \%$ solid loading (Figure 6).

It was clearly observed that the surfactants Tween 20, Tween 80, and BSA obviously increased glucan and xylan conversion, and hence increased ethanol concentration and ethanol yield, compared with no addition of surfactants at either 6 or $9 \%$ glucan loading (Figure 6). One possible reason for this phenomenon may be that surfactants prevented the unproductive binding of the cellulases to the fermentation residues. This allowed more enzyme to be available for the conversion of cellulose, resulting in a higher sugar conversion and hence a higher ethanol yield [39,40]. Another possible reason may be that surfactants increased enzyme stability by reducing the thermal denaturation effect and improving the properties of solvents, and hence the efficiency of enzyme-substrate interaction $[39,40]$. The inhibitory effect of unhydrolyzed solids was the major cause for the poor SSF performance, due to the binding of yeast cells to the solid residues [27]. Surfactants may also improve the cell viability by reducing the unproductive binding of cells to fermentation residues.

It is interesting to note that the highest glucan and $x y-$ lan conversion was obtained with $2 \%$ Tween 20 addition, which increased by $3.8 \%$ and $4.6 \%$ at $6 \%$ glucan loading, and $4.3 \%$ and $5.6 \%$ at $9 \%$ glucan loading, respectively, compared to that without surfactants addition (Figure 6A and 6B). Furthermore, the highest glucose concentration and ethanol yield was also obtained with $2 \%$ Tween 20 addition, and they increased by $7.6 \%$ and $2.2 \%$ at $6 \%$ glucan loading and $5.5 \%$ and $3.1 \%$ at $9 \%$ glucan loading, respectively, compared to that without surfactants addition (Figure 6C and 6D). The results indicated that the addition of $2 \%$ Tween 20 obviously improved the SSF performance of SECS at $6 \%$ and $9 \%$ glucan loading under $39^{\circ} \mathrm{C}$. A previous study also confirmed that ethanol yield increased by $8 \%$ in SSF of steam-pretreated softwood with the addition of Tween-20, and the enzyme activity increased in the liquid fraction at the end of SSF [41]. It should be noted that the industrial process of ethanol production should consider the relations of the cost and environmental effect of surfactants and improved SSF performance. Previous studies have indicated that the surfactants addition in SSF 

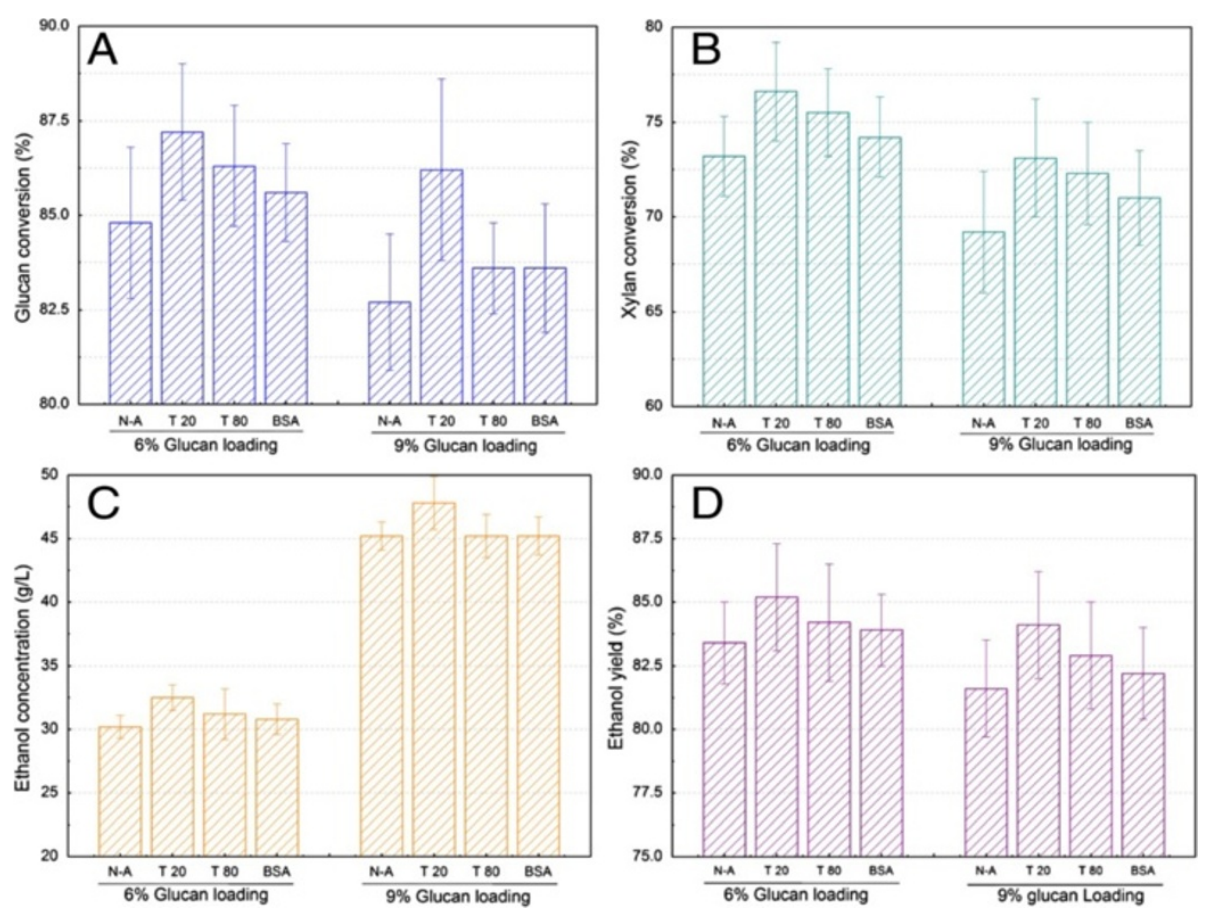

Figure 6 Effects of adding 2.0\% (w/w) Tween 20, Tween 80, and BSA on the SSF performance of SECS. Glucan conversion (A), xylan conversion (B), ethanol concentration (C), and ethanol yield (D) were determined in SSF. The experiments were conducted at inoculation OD 4.0, $\mathrm{pH} 4.8,39^{\circ} \mathrm{C}, 50 \%$ nutrients, and 36 hours pre-hydrolysis time. N-A is Non-addition; T 20 and T 80 is Tween 20 and Tween 80, respectively. BSA, bovine serum albumin; OD, optical density; SSF, simultaneous saccharification and fermentation.

increased the capital cost of biomass conversion process, but surfactants addition reduced the enzyme loading and increased the fermentation performance [39-41]. Meanwhile, surfactants addition decreased the enzyme adsorption onto the solid residue, which should make enzyme recovery recycle from the SSF system possible [39-41]. These studies also suggested that the further work should be conducted to balance the capital cost of surfactant and the SSF performance.

\section{Mass balance comparison between separate hydrolysis and fermentation and simultaneous saccharification and fermentation}

Mass balance is essential to evaluating the biomass conversion process for LCE production [42-45]. For a systematical evaluation of CS conversion process, mass balance studies were performed on the processes of SEP, SHF, SSF, and SSF with $2 \%$ Tween 20 addition at the optimal conditions (Figures 7 and 8). As for SEP, Figure 7 shows that glucan recovery reached $91.6 \%$, which is higher than that for different acid pretreatment at $190^{\circ} \mathrm{C}$ and $90 \mathrm{mM}$ [42]. This indicated that SEP hardly degraded cellulose, which is confirmed by previous studies $[4,12]$. It should be noted that xylan and araban recovery was $61.2 \%$ and $63.8 \%$, respectively, which implied that the hemicelluloses were partly degraded in SEP. The glucan content of SECS solid reached $59.0 \%$ and the acetyl of UCS was removed, which should facilitate the conversion process of CS.

Traditional SHF resulted in low sugar conversion in enzymatic hydrolysis and low ethanol yield in fermentation, likely due to the fact that the enzyme activity was inhibited by products' feedback inhibitory effect. After 96 hours hydrolysis and 96 hours fermentation, a glucose concentration of $101.2 \mathrm{~g} / \mathrm{L}$ and an ethanol concentration of $50.4 \mathrm{~g} / \mathrm{L}$ were obtained at $12 \%$ glucan loading in SHF. This corresponded to a glucan conversion of $69.2 \%$ and an ethanol yield of $66.9 \%$ based on the maximum theoretical yield of glucose presented in SECS biomass. The low processing temperature $\left(30^{\circ} \mathrm{C}\right)$ of traditional SSF limited the hydrolysis rate and hence limited the further improvement of ethanol productivity. Compared with traditional SHF and SSF, 36 hour pre-hydrolysis SSF at $39^{\circ} \mathrm{C}$ obviously increased glucan conversion from 69.2 to $75.2 \%$, and hence increased ethanol yield from 66.9 to $70.2 \%$. The relative glucan conversion and ethanol yield increased by $8.7 \%$ and $5.0 \%$, respectively (Figures $8 \mathrm{~A}$ and $8 \mathrm{~B}$ ). To remove the solid's inhibitory effect on enzymatic hydrolysis and fermentation, 2\% Tween 20 was added in SSF and mass balance was also conducted around the whole process (Figure 8C). Glucan conversion and ethanol yield reached $78.6 \%$ and $77.2 \%$, respectively, and the ethanol concentration reached $59.8 \mathrm{~g} / \mathrm{L}$ in 36 hour pre-hydrolysis SSF with $2 \%$ Tween 20 addition at $39^{\circ} \mathrm{C}$. The relative glucan 


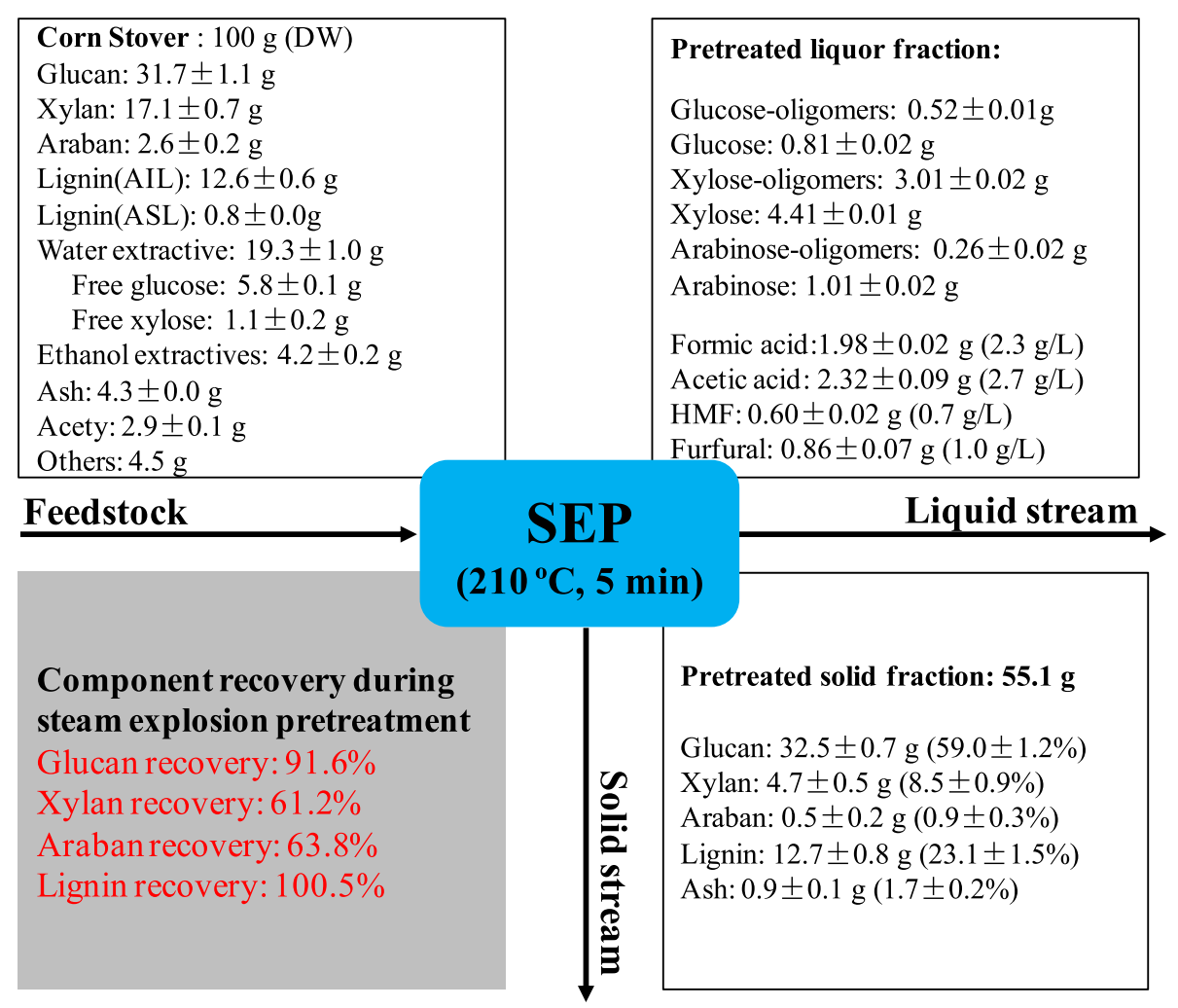

Figure 7 Mass balance analysis for steam explosion pretreatment (SEP) of corn stover biomass at $210^{\circ} \mathrm{C}$ for five minutes. SEP, steam explosion pretreatment; DW, dry weight.

conversion and ethanol yield increased by $4.5 \%$ and $3.5 \%$, respectively, compared with 36 hour pre-hydrolysis SSF at $39^{\circ} \mathrm{C}$. These results indicated that high glucan loading and high temperature obviously improved the SSF performance. Therefore, the SSF of SECS at high glucan loading and high temperature using a novel thermal- and ethanoltolerant $S$. cerevisiae should be an effective conversion process for ethanol production.

\section{Conclusions}

The present results suggest that glucan conversion of SECS is maintained at approximately 71 to $79 \%$, at an enzyme loading of $30 \mathrm{FPU} / g$ glucan, with glucan loading varying from 3 to $12 \%$ in enzymatic hydrolysis. The optimal parameters of SSF include inoculation OD 4.0, initial $\mathrm{pH} 4.8,50 \%$ nutrients, 36 hours pre-hydrolysis time, $39^{\circ} \mathrm{C}$, and $12 \%$ glucan loading (20\% solid loading). Under the optimal conditions, glucan conversion, ethanol yield, and final ethanol concentration of SSF reached 78.6\%, $77.2 \%$, and $59.8 \mathrm{~g} / \mathrm{L}$, respectively, with $2 \%$ Tween 20 addition. The inhibitory effects of DPs, products, and solids were not obvious in SSF at 6 to $12 \%$ glucan loading. Therefore, compared with traditional SHF and SSF, high glucan loading and high temperature obviously improved the SSF performance of SECS using a novel thermal- and ethanol-tolerant strain of S. cerevisiae in this study.

\section{Materials and methods}

\section{Biomass source}

CS biomass used for this study was collected from the suburb of Tianjin, China. CS was air-dried to the moisture content of 5 to $10 \%$. For the composition analysis, CS was milled by knife mill (YS-08, BYZME, Beijing, China), and passed through a 20-mesh screen. The composition analysis was conducted using the Laboratory Analysis Protocol (LAP) of the National Renewable Energy Laboratory, Golden, Colorado, United States. Compositions of UCS are given in Table 1.

\section{Steam explosion pretreatment}

SEP was conducted by a pretreatment unit consisting of a 15-L steam explosion reactor (Tianjin hanyang metal equipment Co., Ltd, Tianjin, China), a 150-L reception chamber (Tianjin hanyang metal equipment Co., Ltd, Tianjin, China), and a steam generator (Jinan Sanheng equipment Co., Ltd, Shandong, China), and followed our previous procedure [12,46]. SEP conditions included: temperature of $210^{\circ} \mathrm{C}$, residence time of five minutes, 


\section{A SHF}

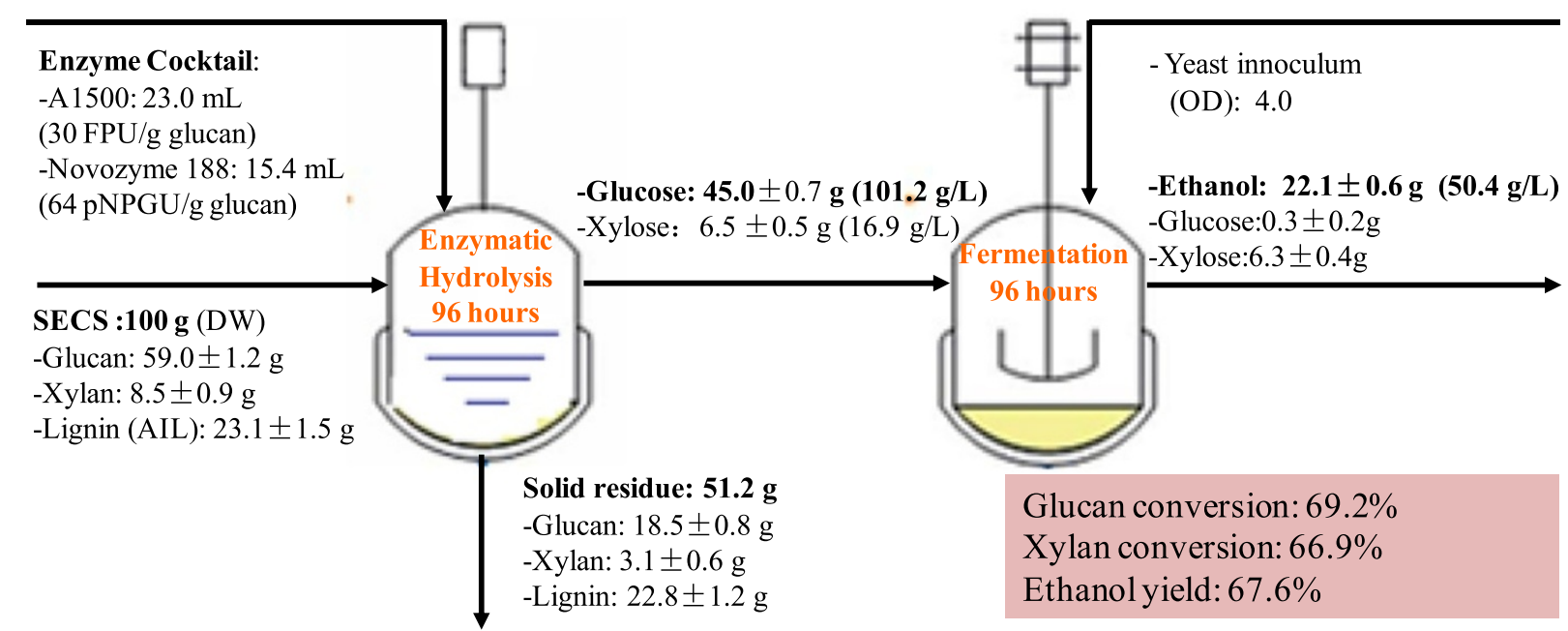

\section{SSF (36 hours pre-hydrolysis)}

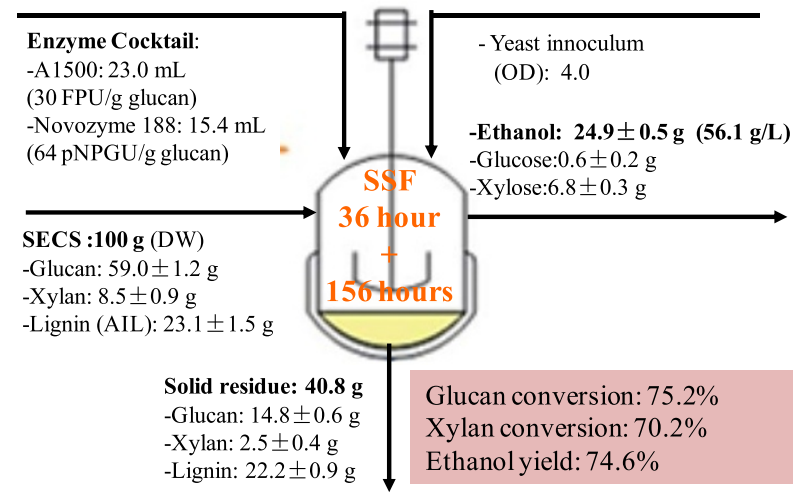

C SSF (36 hours pre-hydrolysis) with $2 \%$ Tween 20

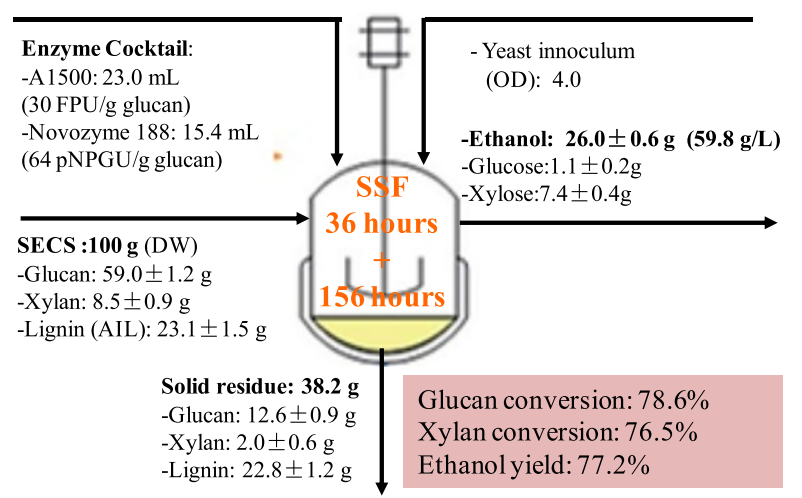

Figure 8 Mass balance analysis for separate hydrolysis and fermentation (SHF) (A), simultaneous saccharification and fermentation (SSF) (B), and SSF with $\mathbf{2 \%}$ Tween 20 (C). For SHF, enzymatic hydrolysis was carried out at pH 4.8, 50 $0^{\circ} \mathrm{C}, 200$ rpm for 96 hours and fermentation of hydrolyzate was conducted at inoculation OD $4.0,30^{\circ} \mathrm{C}, 50 \%$ nutrients, $200 \mathrm{rpm}$ for 96 hours. For SSF, experiments were performed at $39^{\circ} \mathrm{C}$, inoculation OD 4.0, pH 4.8, 50\% nutrients, and 200 rpm for 192 hours. Data were collected from 12\% (w/w) glucan loading experiments of SECS conversion. AlL, acid insoluble lignin; DW, dry weight; FPU, filter paper unit; OD, optical density; PNPGU, p-nitrophenol- $\beta$-D- glucopyranoside units; SECS, steam-exploded corn stover; SHF, separate hydrolysis and fermentation; SSF, simultaneous saccharification and fermentation.

and 30\% initial moisture content. After pretreatment, SECS was separated from the liquid fraction by vacuum filtration using a Buchner funnel (Tianjin shunlongda technology Co., Ltd, Tianjin, China) and then washed with deionized water at solid-to-water ratio 1:15. Compositions of SECS and SEL were analyzed, and the results are shown in Table 1.

\section{Enzymatic hydrolysis}

Accellerase 1500 was a generous gift from Genencor (Jiangsu, China). Novozyme 188 was purchased from Sigma-Aldrich (St Louis, Missouri, United States). The filter paper unit of Accellerase 1500 is $77 \mathrm{FPU} / \mathrm{mL}$, while xylanase and $\beta$-xylosidase is $72 \mathrm{IU} / \mathrm{mL}$ and $23 \mathrm{IU} / \mathrm{mL}$, respectively. The $\beta$-glucosidase activity of Novozyme 188 is
250 p-nitrophenol- $\beta$-D- glucopyranoside units (pNPGU)/mL. SECS was hydrolyzed at different glucan loadings in a $0.05 \mathrm{M}$ citrate buffer solution ( $\mathrm{pH} 4.8)$ with an Accellerase 1500 loading of $15 \mathrm{FPU}, 30 \mathrm{FPU}$, or $60 \mathrm{FPU} / \mathrm{g}$ glucan and a $\beta$-glucosidase loading of $64 \mathrm{pNPGU} / \mathrm{g}$ glucan. The experiments were conducted at $50^{\circ} \mathrm{C}$ and $200 \mathrm{rpm}$ for 168 hours. Hydrolyzate was collected by centrifuging at $10,000 \mathrm{rpm}$ for 10 minutes. The residues were washed with a volume of water equal to 15 times the dry weight of initial SECS. Composition in hydrolyzate and washed liquid were analyzed using HPLC. All these experiments were conducted with two replicates. Glucan conversion was calculated based on that glucan dissolved into the liquor divided by glucan content in SECS. 


\section{Microorganism and seed culture preparation}

S. cerevisiae, angel thermal- and ethanol-tolerant alcohol active dry yeast (product number: 80000012, Angel Yeast Co. Ltd., Hubei, China), was used in this study. The acclimatization of this yeast strain was conducted by multiple rounds of the adaptive culture in inhibitors medium containing acetic acid, furfural, and phenol (Sinopharm Chemical Reagent Co.,Ltd, Shanghai, China). S. cerevisiae can tolerate $5.3 \mathrm{~g} / \mathrm{L}$ acetic acid, $1.3 \mathrm{~g} / \mathrm{L}$ furfural, and 0.5 $\mathrm{g} / \mathrm{L}$ phenol [36]. For seed preparation, S. cerevisiae was cultivated in yeast extract peptone dextrose (YPD) medium (20 g/L glucose, $10 \mathrm{~g} / \mathrm{L}$ yeast extract, and $20 \mathrm{~g} / \mathrm{L}$ peptone) at $30^{\circ} \mathrm{C}$ and $150 \mathrm{rpm}$ for 12 hours. The yeast cells were then inoculated to the secondary seed medium (20 g/L glucose, $10 \mathrm{~g} / \mathrm{L}$ yeast extract, and $20 \mathrm{~g} / \mathrm{L}$ peptone) and cultivated at $30^{\circ} \mathrm{C}$ and $150 \mathrm{rpm}$ for 12 hours. Cell density was measured at $600 \mathrm{~nm}$ (1-cm light path) using a UV-vis spectrometer (Beckman Coulter Inc., California, United States). OD was corrected between 0.1 and 0.7 with the dilution factors as necessary. The initial OD for secondary seed culture was 0.05 .

\section{Separate hydrolysis and fermentation}

For SHF, washed SECS were pre-hydrolyzed with en enzyme loading of $30 \mathrm{FPU} / \mathrm{g}$ glucan at $\mathrm{pH} 4.8,50^{\circ} \mathrm{C}$, and $200 \mathrm{rpm}$ for 96 hours. After pre-hydrolysis, the hydrolyzate was separated from the hydrolysis residues. Hydrolyzate was then transferred into $250 \mathrm{~mL}$ Erlenmeyer flasks capped with rubber stoppers with a working volume of $100 \mathrm{~mL}$. Yeast cell pellets used for inoculation were obtained by centrifuging the seed culture at 5,000 rpm for 10 minutes. Fermentations of hydrolyzate were carried out at $\mathrm{pH} 4.8,30^{\circ} \mathrm{C}$, and $200 \mathrm{rpm}$ for 96 hours. Fermentation samples were taken at different time-points and centrifuged at 10,000 rpm for 10 minutes. Supernatants were filtered through a $0.22-\mu \mathrm{m}$ Whatman syringe filter (Shanghai Wanzi shiye Co., Ltd, Shanghai, China) and analyzed by HPLC. All experiments were conducted with two replicates.

\section{Simultaneous saccharification and fermentation}

SSF experiments were conducted in 250-mL Erlenmeyer flasks with $100 \mathrm{~mL}$ of total mixture for 192 hours at $200 \mathrm{rpm}$. Experimental parameters for SSF of washed SECS and whole slurry are shown in Table 2. The enzyme loading used in SSF is $30 \mathrm{FPU} / \mathrm{g}$ glucan. In SSF, samples were taken at different time-points and centrifuged at $10,000 \mathrm{rpm}$ for 10 minutes. Supernatants were filtered through a $0.22-\mu \mathrm{m}$ Whatman syringe filter. Compositions of liquid fraction and fermentation residues were determined by HPLC. In an attempt to investigate the effects of surfactants on the SSF process, $2 \%(\mathrm{w} / \mathrm{w})$ of Tween 20, Tween 80, and BSA (Tianjin Xiensi biochemistry technology Co., Ltd, Tianjin, China) were added at the beginning of SSF. All these experiments were conducted with two replicates. Ethanol yield in SHF and SSF was calculated based on the maximal theoretical ethanol yield from consumed glucose only, which is $0.51 \mathrm{~g}$ ethanol $/ \mathrm{g}$ glucose. Initial ethanol yield was calculated based on ethanol content divided by the maximal theoretical ethanol content from glucose only, at the first 6 hours fermentation. Final ethanol yield and concentration were calculated at 168 hours fermentation. $100 \% \mathrm{~N}$ stands for $100 \%$ nutrients, which was defined as $10 \mathrm{~g} / \mathrm{L}$ yeast extract and $20 \mathrm{~g} / \mathrm{L}$ peptone; $50 \% \mathrm{~N}$ was defined as $5 \mathrm{~g} / \mathrm{L}$ yeast extract and $10 \mathrm{~g} / \mathrm{L}$ peptone; and $0 \% \mathrm{~N}$ was defined as $0 \mathrm{~g} / \mathrm{L}$ yeast extract and $0 \mathrm{~g} / \mathrm{L}$ peptone (Table 2).

\section{Measurement of viable cell density}

Because it is impossible to measure the OD in SSF of washed SECS and whole slurry, CFU was measured to determine the viable cell density. Fermentation slurry was sampled and diluted using sterile water. $100 \mu \mathrm{L}$ of each diluted sample was taken and plated on an YPD agar medium $(20 \mathrm{~g} / \mathrm{L}$ glucose, $10 \mathrm{~g} / \mathrm{L}$ yeast extract, and $20 \mathrm{~g} / \mathrm{L}$ peptone). The dilution rate for each sample was varied to guarantee that the number of colonies on a single plate was between 20 and 200 . The plates were then cultured at $30^{\circ} \mathrm{C}$ for 48 hours. Single colonies formed on the plates were counted and viable cell density was calculated accordingly.

\section{Analysis methods and mass balance}

Sugars, DPs, glycerol, acetic acid, and ethanol were analyzed using HPLC (Waters, Milford, Massachusetts, United States) with a Biorad Aminex HPX-87H column (Biorad, Hercules, California, United States). Column temperature was maintained at $65^{\circ} \mathrm{C}$. Mobile phase $\left(5 \mathrm{mM} \mathrm{H}_{2} \mathrm{SO}_{4}\right)$ flow rate was $0.6 \mathrm{~mL} / \mathrm{min}$. Mass balance was performed around the whole conversion process of SECS including SEP, enzymatic hydrolysis and fermentation for SHF, and fermentation for SSF. Error bars in the present Tables and Figures represent the standard deviation of the replicates. For all significance tests, Student's t-test was used, requiring a probability $P<0.05$ in order to be significant.

\section{Abbreviations}

BSA: Bovine serum albumin; CFU: Colony forming unit; CS: Corn stover; DPs: Degradation products; FPU: Filter paper unit; HMF: 5-hydroxymethyl furfural; LCC: Lignin-carbohydrate complex; LCE: Lignocellulosic ethanol; OD: Optical density; SECS: Steam-exploded corn stover; SEP: Steam explosion pretreatment; SHF: Separate hydrolysis and fermentation; SSF: Simultaneous saccharification and fermentation; UCS: Untreated corn stover; YPD: Yeast extract peptone dextrose.

\section{Competing interests}

The authors declare that they have no competing interests.

\section{Authors' contributions}

$L Z H, L B Z$, and $Y Y J$ participated in the design of the study. $L Z H$ performed the statistical analysis and drafted the manuscript. LZH, QL, and ZJQ carried out the SSF experiments. QL and LBZ revised the manuscript. All authors provided critical input to the manuscript and read and approved the final manuscript. 


\section{Acknowledgements}

This work was financially supported by the Ministry of Science and Technology of China (863 program: 2012AA02A701), and the National Natural Science Foundation of China (Major International Joint Research Project: 21020102040). Thanks to lab members of professor Yong Kang at School of Chemical Engineering and Technology in Tianjin University for their valuable help on the pretreatment.

Received: 24 June 2014 Accepted: 10 November 2014

Published online: 04 December 2014

\section{References}

1. Harun S, Balan V, Takriff MS, Hassan O, Jahim J, Dale BE: Performance of AFEX ${ }^{\mathrm{TM}}$ pretreated rice straw as source of fermentable sugars: the influence of particle size. Biotechnol Biofuels 2013, 6:40.

2. Yang B, Wyman CE: Pretreatment: the key to unlocking low-cost cellulosic ethanol. Biofuels Bioprod Bioref 2008, 2:26-40.

3. Chen $H Z$, Liu ZH, Dai SH: A novel solid state fermentation coupled with gas stripping enhancing the sweet sorghum stalk conversion performance for bioethanol. Biotechnol Biofuels 2014, 7:53.

4. Chen HZ, Qiu WH: Key technologies for bio-ethanol production from lignocelluloses. Biotechnol Adv 2010, 28:556-562.

5. Himmel ME, Ding SY, Johnson DK, Adney WS, Nimlos MR, Brady JW, Foust TD: Biomass recalcitrance: engineering plants and enzymes for biofuels production. Science 2007, 315:804.

6. Qin L, Liu ZH, Jin MJ, Li BZ, Yuan YJ: High temperature aqueous ammonia pretreatment and post-washing enhance the high solids enzymatic hydrolysis of corn stover. Bioresour Technol 2013, 146:504-511.

7. Zhong C, Cao YX, Li BZ, Yuan YJ: Biofuels in China: past, present and future. Biofuels Bioprod Bioref 2010, 4:326-342.

8. Chundawat SPS, Beckham G, Himmel ME, Dale BE: Deconstruction of lignocellulosic biomass to fuels and chemicals. Annu Rev Chem Biomol Eng 2011, 2:121-145.

9. Mosier N, Wyman C, Dale BE, Elander R, Lee YY, Holtzapple M, Ladisch M Features of promising technologies for pretreatment of lignocellulosic biomass. Bioresour Technol 2005, 96:673-686.

10. Wyman CE, Dale BE, Elander RT, Holtzapple M, Ladisch MR, Lee YY Coordinated development of leading biomass pretreatment technologies. Bioresour Technol 2005, 96:1959-1966.

11. Alvira P, Tomás-Pejó E, Ballesteros M, Negro MJ: Pretreatment technologies for an efficient bioethanol production process based on enzymatic hydrolysis: a review. Bioresour Technol 2010, 101:4851-4861.

12. Liu ZH, Qin L, Pang F, Jin MJ, Li BZ, Kang Y, Dale BE, Yuan YJ: Effects of biomass particle size on steam explosion pretreatment performance for improving the enzyme digestibility of corn stover. Ind Crop Prod 2013, 44:176-184.

13. Zhao JY, Chen HZ: Correlation of porous structure, mass transfer and enzymatic hydrolysis of steam exploded corn stover. Chem Eng Sci 2013, 104:1036-1044.

14. Wang L, Liu ZH, Duan YY, Chen HZ: Relations between substrate morphological change and oxygen transfer in solid-state fermentation (SSF) using Penicillium decumbens JUA10. J Chem Technol Biot 2014, 89:1582-1589

15. Öhgren K, Bura R, Lesnicki G, Saddler J, Zacchi G: A comparison between simultaneous saccharification and fermentation and separate hydrolysis and fermentation using steam-pretreated corn stover. Process Biochem 2007, 42:834-839.

16. Lu J, Li XZ, Yang RF, Zhao J, Qu YB: Tween 40 pretreatment of unwashed water-insoluble solids of reed straw and corn stover pretreated with liquid hot water to obtain high concentrations of bioethanol. Biotechnol Biofuels 2013, 6:159.

17. Taherzadeh MJ, Karimi K: Enzyme-based hydrolysis processes for ethanol from lignocellulosic materials: a review. Bioresources 2007, 2:707-738

18. Koppram R, Tomás-Pejó E, Xiros C, Olsson L: Lignocellulosic ethanol production at high-gravity: challenges and perspectives. Trend Biotechnol 2014, 32:46-53.

19. Modenbach AA, Nokes SE: Enzymatic hydrolysis of biomass at high-solids loadings-a review. Biomass Bioenerg 2013, 56:526-544.

20. Modenbach AA, Nokes SE: The use of high-solids loadings in biomass pretreatment-a review. Biotechnol Bioeng 2012, 109:1430-1442.
21. Moreno AD, Tomás-Pejó E, Ibarra D, Ballesteros M, Olsson L: Fed-batch SSCF using steam-exploded wheat straw at high dry matter consistencies and a xylose-fermenting Saccharomyces cerevisiae strain: effect of laccase supplementation. Biotechnol Biofuels 2013, 6:160.

22. Lu YF, Wang YH, Xu GQ, Chu J, Zhuang YP, Zhang SL: Influence of high solid concentration on enzymatic hydrolysis and fermentation of steamexploded corn stover biomass. Appl Biochem Biotechnol 2010, 160:360-369.

23. Klinke $H B$, Thomsen $A B$, Ahring BK: Inhibition of ethanol-producing yeast and bacteria by degradation products produced during pre-treatment of biomass. Appl Microbiol Biotechnol 2004, 66:10-26.

24. Hodge DB, Karim MN, Schell DJ, McMillan JD: Soluble and insoluble solids contributions to high-solids enzymatic hydrolysis of lignocelluloses. Bioresour Technol 2008, 99:8940-8948.

25. Jørgensen H, Vibe-Pedersen J, Larsen J, Felby C: Liquefaction of lignocellulose at high-solids concentrations. Biotechnol Bioeng 2007, 96:862-870.

26. Jin MJ, Gunawan C, Balan V, Dale BE: Consolidated bioprocessing (CBP) of AFEX ${ }^{\mathrm{TM}}$-pretreated corn stover for ethanol production using clostridium phytofermentans at a high solids loading. Biotechnol Bioeng 2012, 109:1929-1936.

27. Jin MJ, Lau MW, Balan V, Dale BE: Two-step SSCF to convert AFEX-treated switchgrass to ethanol using commercial enzymes and Saccharomyces cerevisiae 424A (LNH-ST). Bioresour Technol 2010, 101:8171-8178.

28. Olofsson K, Bertilsson M, Lidén G: A short review on SSF-an interesting process option for ethanol production from lignocellulosic feedstocks. Biotechnol Biofuels 2008, 1:7.

29. Srichuwong S, Fujiwara M, Wang XH, Seyama T, Shiroma R, Arakane M, Mukojima N, Tokuyasu K: Simultaneous saccharification and fermentation (SSF) of very high gravity (VHG) potato mash for the production of ethanol. Biomass Bioenerg 2009, 33:890-898.

30. Martína C, Thomsen MH, Hauggaard-Nielsen $H$, Thomsen AB: Wet oxidation pretreatment, enzymatic hydrolysis and simultaneous saccharification and fermentation of clover-ryegrass mixtures. Bioresour Technol 2008, 99:8777-8782

31. Jin MJ, Balan V, Gunawan C, Dale BE: Consolidated bioprocessing (CBP) performance of clostridium phytofermentans on AFEX-treated corn stover for ethanol production. Biotechnol Bioeng 2011, 108:1290-1297.

32. Lynd LR, Baskaran S, Casten S: Salt accumulation resulting from base added for $\mathrm{pH}$ control, and not ethanol, limits growth of Thermoanaerobacterium thermosaccharolyticum HG-8 at elevated feed xylose concentrations in continuous culture. Biotechnol Prog 2001, 17:118-125.

33. Wilkins MR, Widmer WW, Grohmann K: Simultaneous saccharification and fermentation of citrus peel waste by Saccharomyces cerevisiae to produce ethanol. Process Biochem 2007, 42:1614-1619.

34. Hoyer K, Galbe M, Zacchi G: Production of fuel ethanol from softwood by simultaneous saccharification and fermentation at high dry matter content. J Chem Technol Biot 2008, 84:570-577.

35. Jönsson LJ, Alriksson B, Nilvebrant N: Bioconversion of lignocellulose: inhibitors and detoxification. Biotechnol Biofuels 2013, 6:16.

36. Ding $M Z$, Wang $X$, Yang $Y$, Yuan $Y J$ : Comparative metabolic profiling of parental and inhibitors-tolerant yeasts during lignocellulosic ethanol fermentation. Metabolomics 2012, 8:232-243.

37. Rudolf A, Baudel H, Zacchi G, Hahn-Hagerdal B, Liden G: Simultaneous saccharification and fermentation of steam-pretreated bagasse using Saccharomyces cerevisiae TMB3400 and Pichia stipitis CBS6054. Biotechnol Bioeng 2008, 99:783-790

38. Roche CM, Dibble CJ, Knutsen JS, Stickel JJ, Liberatore MW: Particle concentration and yield stress of biomass slurries during enzymatic hydrolysis at high-solids loadings. Biotechnol Bioeng 2009, 104:290-300

39. Kumar R, Wyman CE: Effect of additives on the digestibility of corn stover solids following pretreatment by leading technologies. Biotechnol Bioeng 2009, 102:1544-1557.

40. Yang B, Wyman CE: BSA treatment to enhance enzymatic hydrolysis of cellulose in lignin containing substrates. Biotechnol Bioeng 2006, 94:611-617.

41. Alkasrawi M, Eriksson T, Börjesson J, Wingren A, Galbe M, Tjerneld F, Zacch $G$ : The effect of Tween-20 on simultaneous saccharification and fermentation of softwood to ethanol. Enzyme Microb Tech 2003, 33:71-78.

42. Qin L, Liu ZH, Li BZ, Dale BE, Yuan YJ: Mass balance and transformation of corn stover by pretreatment with different dilute organic acids. Bioresour Technol 2012, 112:319-326.

43. Li BZ, Balan V, Yuan YJ, Dale BE: Process optimization to convert forage and sweet sorghum bagasse to ethanol based on ammonia fiber expansion (AFEX) pretreatment. Bioresour Technol 2010, 101:1285-1292. 
44. Krishnan C, Sousa LD, Jin MJ, Chang LP, Dale BE, Balan V: Alkali-based AFEX pretreatment for the conversion of sugarcane bagasse and cane leaf residues to ethanol. Biotechnol Bioeng 2010, 107:441-450.

45. Uppugundla N, da Costa SL, Chundawat SPS, Yu XR, Simmons B, Singh S, Gao XD, Kumar R, Wyman CE, Dale BE, Balan V: A comparative study of ethanol production using dilute acid, ionic liquid and $\mathrm{AFEX}^{\mathrm{TM}}$ pretreated corn stover. Biotechnol Biofuels 2014, 7:22.

46. Liu ZH, Qin L, Jin MJ, Pang F, Li BZ, Kang Y, Dale BE, Yuan YJ: Evaluation of storage methods for the conversion of corn stover biomass to sugars based on steam explosion pretreatment. Bioresour Technol 2013, 132:5-15.

doi:10.1186/s13068-014-0167-x

Cite this article as: Liu et al: Simultaneous saccharification and

fermentation of steam-exploded corn stover at high glucan loading and high temperature. Biotechnology for Biofuels 2014 7:167.

\section{Submit your next manuscript to BioMed Central and take full advantage of:}

- Convenient online submission

- Thorough peer review

- No space constraints or color figure charges

- Immediate publication on acceptance

- Inclusion in PubMed, CAS, Scopus and Google Scholar

- Research which is freely available for redistribution 